\title{
Penggunaan Kombinasi Replacement, Shear Key Dan Timbunan Sebagai Salah Satu Alternatif Perbaikan Tanah Ekspansif Untuk Jalan Raya
}

\author{
Rafie Pradipta ${ }^{1}$, Mila Kusuma $\mathbf{W}^{2}$ \\ ${ }^{1}$ Program Studi Teknik Sipil, Fakultas Teknik Sipil dan Perencanaan, Institut Teknologi AdhiTama Surabaya \\ ${ }^{2}$ Program Studi Teknik Sipil, Fakultas Teknik Sipil dan Perencanaan, Institut Teknologi AdhiTama Surabaya \\ Email: ${ }^{1}$ rafiepradipta7@gmail.com, ${ }^{2}$ milakusuma@itats.ac.id
}

\begin{abstract}
The construction of highway construction on expansive soil in the post-construction period needs to be reviewed for the condition of the soil improvement methods used. STA $86+399-$ STA $86+400$ suffered damage in the post-construction period. The soil repair method used when damaged is by adding a Shear-key to the foot of the pile. The use of the Shear - Key complements the previous soil improvement method where there is a Replacement as deep as $1.5 \mathrm{~m}$ with Dumps. The function of the Shear - Key is expected to be a moisture barrier so that the condition of the subgrade can be maintained its water content. Shear - Key is construction under embankment feet with dimensions of $1.5 \mathrm{~m}$ high and $4 \mathrm{~m}$ wide with compacted fine sand material. In STA $86+399-$ STA $86+400$ an analysis of the three improvement methods will be performed. From the results of modeling using Seep / W shows that the amount of seepage that occurs in the presence of a small Shear - Key is $6 \times 10-6-1 \times 10-5 \mathrm{~m} / \mathrm{sec}$ compared without shear - key of 0.5-1 m/ sec. Whereas in the condition of stability analysis with the Shear-Key which experienced a slight change in the safety number, the magnitude of the landslide field and the depth of the landslide. The effect of changes in groundwater level on the stability analysis using the Shear-Key when MAT is tried at depths $>1.0 \mathrm{~m}$, the value of the security number drops to $\pm 4 \%$ compared without using the Shear-key. the change in safety numbers that occur is still considered safe because of the SF value> 1.5 with the use of a combination of repair replacement, embankment, Shear - Key during the Construction.
\end{abstract}

Keywords: expansive soil, replacement, embankment, shear - key, Seep/W

\begin{abstract}
Abstrak
Pembangunan konstruksi jalan raya diatas tanah ekspansif pada masa pasca konstruksi perlu ditinjau kembali kondisi metode perbaikan tanah yang digunakan. STA $86+399$ - STA $86+400$ mengalami kerusakan pada masa pasca konstruksi. Metode perbaikan tanah yang digunakan pada saat mengalami kerusakan yaitu dengan menambahkan Shear - Key di kaki timbunan. Penggunaan Shear - Key ini melengkapi metode perbaikan tanah sebelumnya dimana ada Replacement sedalam 1,5 m dengan Timbunan. Fungsi dari Shear - Key diharapkan dapat menjadi moisture barrier sehingga kondisi tanah dasar dapat terjaga kadar airnya. Shear - Key adalah pembuatan kaki di bawah kaki timbunan dengan dimensi tinggi 1,5 $\mathrm{m}$ dan lebar $4 \mathrm{~m}$ dengan material pasir halus yang dipadatkan. Pada STA 86+399 - STA 86+400 akan dilakukan analisis dari ketiga metode perbaikan. Dari hasil pemodelan menggunakan Seep/W menunjukkan bahwa besarnya rembesan yang terjadi dengan adanya Shear - Key kecil yaitu $6 \times 10^{-6}-1 \times 10^{-5} \mathrm{~m} /$ det dibandingkan tanpa Shear - Key sebesar 0.5 $1 \mathrm{~m} /$ det. Sedangkan pada kondisi analisis stabilitas dengan adanya Shear - Key yang mengalami sedikit perubahan pada angka keamanan, besarnya bidang longsor dan kedalaman kelongsoran. Pengaruh perubahan muka air tanah pada analisis stabilitas menggunakan Shear -Key bila MAT dicoba pada kedalaman $>1,0 \mathrm{~m}$ nilai angka kemanan turun hingga $\pm 4 \%$ dibandingkan tanpa menggunakan Shear - Key. Perubahan angka kemananan yang terjadi masih dikategorikan aman karena nilai SF > 1.5 dengan penggunaan kombinasi perbaikan replacement, timbunan dan ShearKey pada masa Konstruksi.
\end{abstract}

Kata Kunci: tanah ekspansif, replacement, timbunan, shear-key, Seep-W 


\section{Pendahuluan}

Tanah ekspansif adalah tanah yang mempunyai sensitifitas tinggi terhadap air, sehingga mengakibatkan tanah akan mudah mengembang dan menyusut [1]. Kandungan mineral Montmorillonite pada tanah ekpansif adalah penyebab dimana tanah memiliki kemampuan kembang susut [2]. Sehingga masalah untuk semua konstruksi yang dibangun diatas tanah ekspansif adalah perubahaan kadar air akibat dari kemampuan menyerap dan mengeluarkan air. Pada konstruksi jalan raya kerusakan yang sering muncul adalah retakan, pengangkatan tanah, penurunan tanah dan longsoran.

Jalan Tol Solo Mantingan - Ngawi pada STA 86 +399 - STA 86+400 mengalami kerusakan di badan jalan pasca konstruksi. Penyebab runtuhnya badan jalan diakibatkan karena jenis tanah pada subgrade merupakan tanah ekspansif dengan nilai rata-rata IP 54,5\% berdasarkan uji Laboratorium. Selain uji laboratorium diperoleh data tanah yaitu NSPT dimana ketebalan tanah eksspansif adalah $9 \mathrm{~m}$ dengan tinggi timbunan yang direncanakan adalah $2.5 \mathrm{~m}$. Metode perbaikan yang dilakukan pada saat konstruksi adalah metode replacement dan timbunan. Kedalaman Replacement yang digunakan pada konstruksi adalah 1,5 m. Sehingga pada pasca kontruksi karena terjadi kerusakan maka metode perbaikan yang dilakukan yang dapat dilakukan adalah membuat suatu konstruksi tambahkan yaitu dengan penggunaan Shear - key .

Penggunaan metode perbaikan tanah menggunakan Replacement yaitu dengan mengganti ke tanah yang lebih baik dapat diaplikasikan pada tanah ekspansif. Metode replacement yang dilakukan pada permukaan tanah ekspansif adalah salah satu metode yang dapat diaplikasikan, namun lebih baik jika dapat mengidentifikasi active zone terlebih dahulu sebelum melakukan metode tersebut [3]. Kedalaman tanah yang akan diganti minimal 1,0 m. Namun pada tanah ekspansif yang tebal metode replacement perlu dipertimbangkan dari segi ketebalan dan sisi ekonomis. Material replacement perlu dipertimbangkan karena berat dari tanah pengganti ini setidaknya mampu untuk menahan beban serta menahan gaya angkat tanah eskpansif dibawah tanah pengganti[4].

Shear-key memiliki fungsi sebagai moisture barrier atau menstabilkan kadar air pada tanah ekspansif dan menjaga pergerakan dari tanah replacement yang diakibatkan oleh beban timbunan dan beban lalu lintas, sedangkan bentuk dari shear-key seperti parit yang memiliki fungsi sebagai saluran drainase. Material dalam metode shear-key menggunakan tanah pasir halus yang dipadatkan, dimensi perencanaan yaitu tinggi $1,5 \mathrm{~m}$ dan lebar $4 \mathrm{~m}$.

Pada perencanaan metode perbaikan tanah dengan timbunan diperlukan beberapa tahapan analisa yaitu meliputi besarnya penurunan akibat tanah timbunan dan nilai stabilitas timbunan [5]. Metode Irisan merupakan metode yang popular dalam kesetimbangan lereng tipe transasional. Perhitungan faktor keamanan harus dilakukan pada sejumlah bidang runtuh sehingga diperoleh suatu bidang runtuh kritis. Bidang runtuh kritis adalah bidang runtuh yang menghasilkan faktor keamanan terkecil. Penentuan bidang runtuh kritis dapat dilakukan dengan cara coba-coba atau menggunakan metode optimasi[6].

Slope/W 2012 merupakan menu dari program Geo Studio yang berfungsi untuk menghitung angka keamanan dan kemiringan. Slope/W dapat menganalisis masalah baik secara sederhana maupun kompleks dengan menggunakan salah satu dari delapan metode kesetimbangan batas untuk berbagai permukaan miring, kondisi tekanan air[7].

Seep/ $W$ adalah juga merupakan salah satu produk aplikasi finite elemen program GeoStudio yang dapat digunakan menganalisis masalah rembesan serta tekanan air pori. Pada dasarnya semua masalah yang berhubungan dengan air tanah dapat diselesaikan menggunakan Seep/W [8]. Seep/W adalah program yang dapat digunakan untuk memodelkan cukup efektif tingkat rembesan dan tekanan preatic permukaan, dengan kondisi tanah dasar yang seragam dan tidak seragam[9]. Dalam pemodelan dapat dikondisikan seperti kondisi aliran, kondisi batas (boundary condition) untuk mengetahui bentuk arah rembesan, volume air dan fungsi konduktivitas.

Pada ruas jalan Tol di STA 86+399 ini akan dilakukan analisis penggunaan kombinasi dari replacement, timbunan serta Shear - key sebagai salah satu alternatif perbaikan tanah ekspansif. Proses pembangunan Shear - Key di kaki timbunan perlu dicek analisis stabilitas yang ditinjau adalah angka keamanan, kedalaman dan panjang potensi kelongsoran dibandingkan tanpa Shear - Key. Sedangkan pada konstruksi penggunaan Shear - key akan dianalisis besarnya rembesan yang terjadi di dalam tanah 
menggunakan program bantu Seep/W. Nilai rembesan yang dianalisis meliputi kecepatan rembesan, tekanan air pori dan tinggi total yang dimana dapat menganalisis arah rembesan yang terjadi didalam tanah. Sehingga dalam penggunaan ketiga alternative perbaikan tanah pada STA 86+399 - STA 86+400 dapat mengurangi terjadinya kerusakan akibat kondisi tanah dasar dan pembebanan.

\section{Metode}

Metode yang digunakan dalam analisis penggunaan kombinasi replacement, Shear - Key dan timbunan adalah sebagai berikut :

1. Analisis parameter data tanah pada STA $86+399-$ STA $86+400$ serta pengujian Laboratorium pada tanah Shear - Key meliputi komponen yang digunakan untuk analisa stabilitas dan analisis rembesan.

2. Menganalisis besarnya rembesan yang terjadi pada tanah dasar dengan Konstruksi shear key dan penggunaan replacement. Apabila kondisi rembesan pada kosntruksi Shear - key

3. Menganalisis stabilitas yang terjadi di tanah dasar dengan kondisi tanpa Shear-Key dan menggunakan Shear- Key. Kondisi stabilitas yang digunakan adalah dengan tanah dasar dengan replacement. Pada analisis ini juga termasuk dengan mencoba ketinggian muka air Tanah karena akan berpengaruh dalam analisa rembesan.

\section{Hasil dan Pembahasan}

\section{Analisis Data Tanah}

Data tanah yang digunakan adalah hasil penyelidikan NSPT sedalam $16.50 \mathrm{~m}$ dimana tanah ekspansif yang diperoleh adalah tanah dengan konsistensi very soft to medium stiff. Nilai NSPT tanah medium yang diperoleh adalah sampai pada kedalaman $9 \mathrm{~m}$ dengan nilai NSPT 13. Penyelidikan laboratorium yang menunjukkan besarnya tegangan overbudden yang terjadi sebesar $3.69 \mathrm{t} / \mathrm{m}^{2}$.

Tanah material Shear - key dilakukan pengujian laboratorium sebanyak 2 sampel tanah dengan kondisi undisturbed, guna memperoleh parameter sifat fisik, kekuatan geser serta nilai koefisien rembesan. Berdasarkan yang dilakukan material tanah Shear - key diperoleh jenis tanah pasir dengan karakteristik tanah yaitu wc $26,5 \%, \gamma \mathrm{t} 1.79 \mathrm{t} / \mathrm{m}^{3}, \phi 48.24^{\circ}, \mathrm{Cu} 0,1705 \mathrm{~kg} / \mathrm{cm}^{2}$, dan nilai rembesan $1,1 \mathrm{x}$ $10^{-3} \mathrm{~cm} /$ detik.

\section{Analisis Rembesan setelah menggunakan Shear - Key dengan Program Bantu Seep/W}

Pemodelan yang dilakukan menggunakan Seep/W menggunakan parameter awal adalah seperti pada Gambar 1. Boundary Condition pada Seep/W digunakan untuk menentukan area yang boleh terjadi rembesan atau tidak terjadi rembesan. Area yang terjadi rembesan ditandai dengan warna biru sedangkan area yang tidak terjadi rembesan ditandai dengan warna merah. Pada lapisan tanah asli dibawah Replacement dianggap mempunyai potensi mengalami rembesan akibat dari genangan air Pada Shear Key. Apabila dari pemodelan dimensi awal Shear - Key memenuhi beberapa kriteria sebagai moisture barrier maka tidak dilakukan perubahan dimensi serta analisis dilanjutkan pada analisis stabilitas akibat perubahan bentuk konstruksi di kaki timbunan.

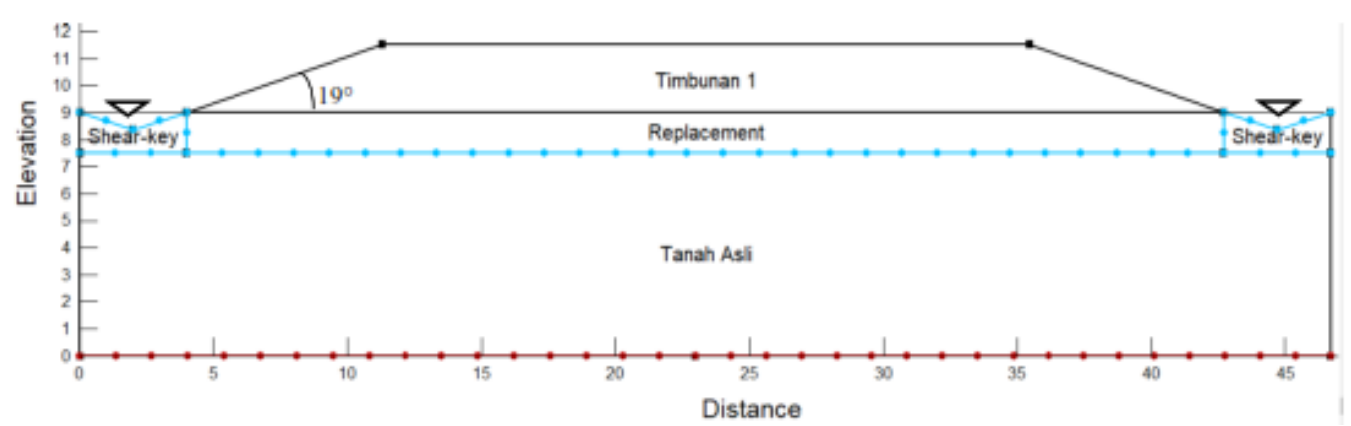

Gambar 1. Pemodelan Timbunan dengan Shear - key menggunakan Seep/W 
Data yang dimasukkan kedalam program Seep/W adalah nilai saturated xconductivity, VWC, dan Mv. Saturated xconductivity adalah nilai koefisien rembesan dalam keadaan jenuh, sedangkan fungsi VWC menyatakan perbedaan kadar air yang bertambah atau hilang akibat curah hujan. Dalam analisis ini digunakan metode steady state tidak terjadi airan di sebelah kiri dan kanan Karena dalam kasus ini tidak terdapat data cuah hujan sehingga pemodelan ini menggunakan metode steady state yang berarti tidak ada perubahan tekanan air pori terhadap waktu maka nilai VWC diabaikan. Tinggi timbunan $2,5 \mathrm{~m}$, kemiringan lereng $19^{\circ}$, kedalaman tanah lunak $9 \mathrm{~m}$ dan tanah replacement sedalam 1,5 $\mathrm{m}$ serta kondisi MAT pada ketinggian $0 \mathrm{~m}$.

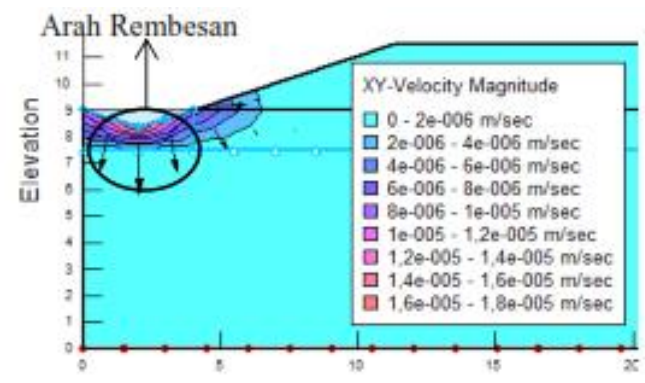

(a) Kondisi dengan Shear-key

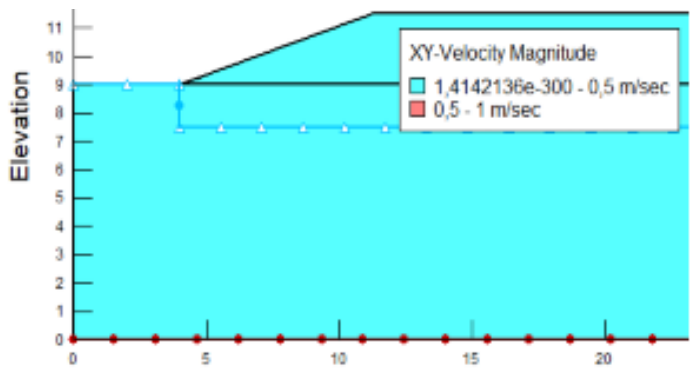

(b) Kondisi tanpa Shear - Key

Gambar 2 Output Dari Pemodelan Menggunakan Seep/W

Gambar 2 menunjukkan bahwa rembesan yang besar terjadi di area Shear - key masih menunjukkan warna biru tua dengan nilai mencapai $6 \times 10^{-6}-1 \times 10^{-5} \mathrm{~m} / \mathrm{det}$ yang menunjukkan terjadi aliran air namun kecil . Nilai rembesan yang diperoleh tersebut mampu mampu memperkecil nilai kecepatan aliran rembesan sebesar $\pm 99 \%$ dibanding kondisi tanpa Shear - key. Kondisi ini juga dipengaruhi oleh material Shear-Key merupakan pasir yang dipadatkan sehingga air akan sulit meresap ke dalam tanah.

Arah aliran rembesan terjadi akibat dari perbedaan tinggi energi total (total head), bukan karena perbedaan tekanan air pori. Arah rembesan ditentukan dari nilai tinggi energi total yang besar ke yang kecil. Dengan adanya rembesan itu maka akan mempengaruhi tekanan air pori kemudian akan mempengaruhi tegangan efektif dan kekuatan geser tanah [10]. Gambar 3 menunjukkan dimana pada kondisi dengan Shear - Key di tanah dasar tekanan air pori yang terjadi sebesar $0 \mathrm{kPa}$, dibandingkan tanpa Shear - Key terjadi tekanan air pori yang menunjukkan besar nilai rembesan terjadi di tanah dasar.
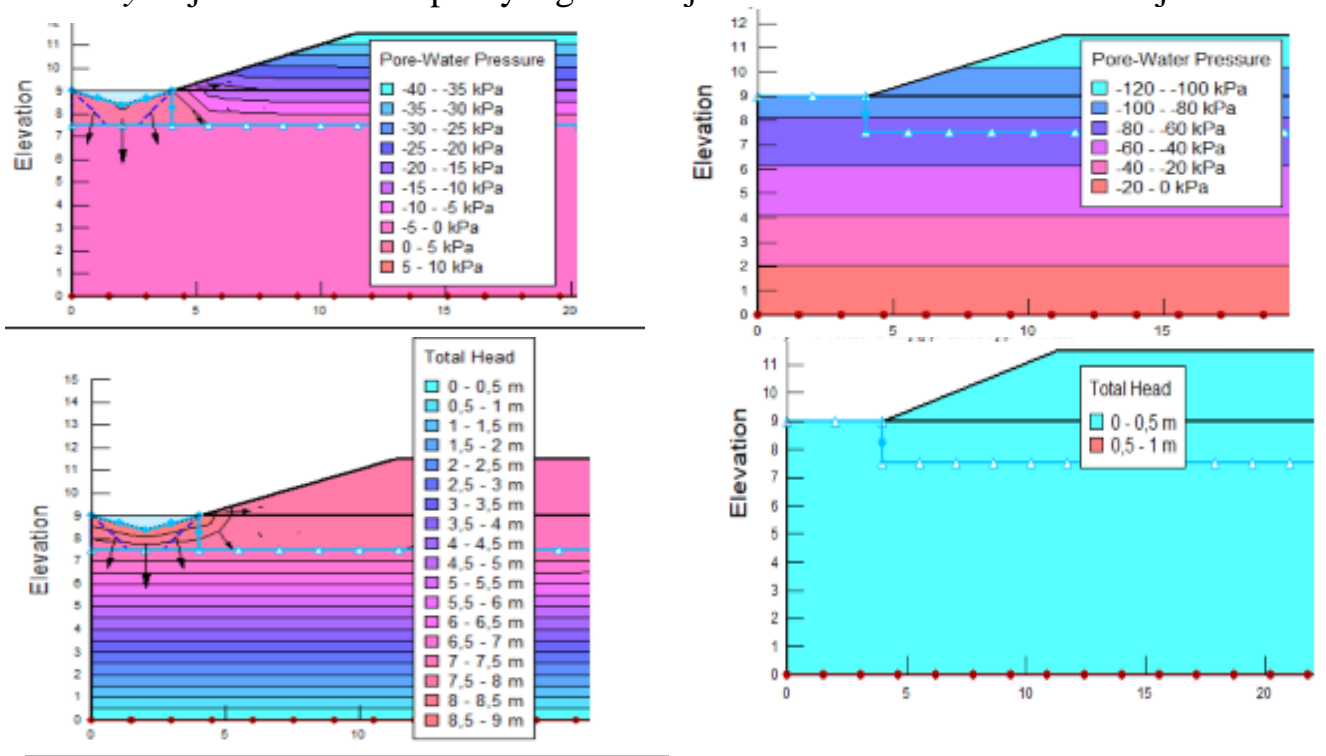

Gambar 3 Output Tekanan air pori dan Total Head Menggunakan Seep/W 


\section{Analisis Stabilitas Timbunan Dengan Replacement Pada Kondisi Dengan Dan Tanpa Shear - Key}

Shear-key yang terletak disebelah kaki timbunan menyebabkan perubahan material dan bentuk pada tanah dasar, sehingga dengan perubahan material tersebut perlu dianalisis stabilitas timbunan. Analisis stabilitas juga dilakukan untuk menghitung nilai angka keamanan dengan Shear-Key dan tanpa Shear-Key. Metode analisis stabilitas yang digunakan adalah dengan menggunakan Bishop. Dalam metode ini, pengaruh gaya-gaya pada sisi tepi tiap irisan diperhitungkan [11]. Persamaan faktor aman pada Bishop membutuhkan cara coba-coba, karena nilai faktor aman (F) terdapat di kedua sisi. selain itu dari metode analisis kesetimbangan batas pada timbunan, penggunaan metode Bishop dianggap mendekati kondisi real di lapangan [12]. Hasil analisis stabilitas menggunakan pengaruh muka air tanah dicoba - coba dalam 3 kondisi yaitu pada kedalaman $0 \mathrm{~m}, 1.5 \mathrm{~m}$ dan $3.0 \mathrm{~m}$. Tabel 1 menunjukkan hasil analisis stabilitas mulai dari angka keamanan, Kedalaman longsor, panjang longsor, radius, momen resistance, serta driven moment.

Tabel 1 Hasil Analisis Stabilitas Pada Timbunan Dengan Replacement

\begin{tabular}{llcccccc}
\hline Kondisi & Kondisi MAT & nilai SF & $\begin{array}{c}\text { H longsor } \\
\mathrm{m}\end{array}$ & $\begin{array}{c}\text { Llongsor } \\
\mathrm{m}\end{array}$ & $\begin{array}{c}\text { radius } \\
\mathrm{m}\end{array}$ & $\begin{array}{c}\text { Mr } \\
\mathrm{kN}-\mathrm{m}\end{array}$ & $\begin{array}{c}\text { Md } \\
\mathrm{kN}-\mathrm{m}\end{array}$ \\
\hline \multirow{2}{*}{$\begin{array}{c}\text { Tanpa Shear } \\
\text { Key }\end{array}$} & MAT 0.0 m & 3.489 & 3.02 & 5.33 & 8.39 & 5023.17 & 1435.92 \\
& MAT 1.5 m & 4.736 & 5.11 & 4.01 & 10.13 & 8147.83 & 1720.56 \\
& MAT 3.0 m & 5.166 & 3.3 & 3.02 & 8.39 & 5406.15 & 1046.46 \\
\hline & MAT 0.0 m & 3.488 & 3.02 & 4.2 & 7.25 & 3454 & 990.28 \\
Shear - Key & MAT 1.5 m & 4.544 & 3.02 & 4.19 & 7.25 & 4929.93 & 1084.93 \\
& MAT 3.0 m & 4.981 & 3.45 & 3.02 & 8.42 & 5660.2 & 1136.32 \\
\hline
\end{tabular}

Berdasarkan Tabel 1 menujukkan bahwa dengan Shear- key di kaki lereng timbunan maka angka keamanan (SF) timbunan lebih kecil dibandingkan dengan yang tidak memakai Shear-Key. Meskipun nilai angka keamanan berbeda namun ketinggian atau panjang kelongsoran yang diperoleh hampir sama pada kondisi muka air yang sama. Kondisi yang menujukkan perbedaan adalah ketika MAT 1.5 m pada kondisi Tanpa Shear - Key bentuk kedalaman kelongsoran lebih dalam namun panjang kelongsoran lebih pendek dibandingkan menggunakan Shear - Key.

Pada kondisi MAT 1,5 m nilai SF menggunakan Shear - Key 4,544< 4,736 kondisi Tanpa Shear - Key. Perbedaan ini disebabkan karena adanya pengupasan pada sebelah kaki timbunan yang difungsikan sebagai saluran sehingga mengurangi momen penahan terhadap timbunan. Ketinggian muka air tanah sedikit berpengaruh terhadap nilai angka keamanan timbunan, dimana bila MAT $>1.0$ m maka nilai angka keamanan turun menjadi $\pm 4 \%$ dari kondisi tanpa Shear - Key.

\section{Kesimpulan}

Berdasarkan analisis dari pemodelan dapat diperoleh kesimpulan sebagai berikut :

1. Material tanah pada shear - key berdasarkan uji laboratorium adalah tanah pasir diperoleh dari nilai rembesan sebesar $1,1 \times 10^{-3} \mathrm{~cm} /$ detik.

2. Nilai koefesien rembesan yang terjadi bila dibandingkan tanpa penggunaan Shear - Key menunjukkan besarnya $6 \times 10^{-6}-1 \times 10^{-5} \mathrm{~m} /$ det yang menunjukkan terjadi aliran air namun kecil . Nilai tersebut mendukung besarnya tekanan air pori dibawah Shear - Key dimana nilainya adalah sebesar $0 \mathrm{kPa}$ yang berarti besarnya aliran air tidak menimbulkan tegangan air pori.

3. Penggunaan Shear - key di kaki timbunan hanya sedikit mempengaruhi perubahan nilai SF, kondisi ini karena adanya sedikit gangguan struktur di kaki timbunan. Bila dicoba - coba dengan kondisi 
MAT berbeda, analisis stabilitas pada timbunan dengan Shear - key menghasilkan nilai SF yang berubah $\pm 4 \%$ menurun bila dibandingkan bila tanpa Shear $-k e$ dengan MAT $>1,0 \mathrm{~m}$.

\section{Referensi}

[1] Sudjianto, A.T., "Tanah Ekspansif karakteristik dan Pengukuran Perubahan Volume", Yogyakarta, Graha Ilmu.

[2] Chen, F. H.. "Foundations on Expansive Soils", Development in Geotechnical Engineering 54, Elsevier Science Publishers B. V, 1988.

[3] International Building Code (IBC) 2006 \& International Residential Code (IRC), 2006.

[4] Pd T-11-2004-B, "Penanganan Tanah Ekspansif dengan Geomembran sebagai Penghalang Kelembaban Vertikal", Departemen Permukiman dan Prasarana Wilayah, 2004.

[5] Mochtar, I. B., "Teknologi Perbaikan Tanah dan Alternatif Perencanaan pada Tanah Bermasalah (Problematic Soils)", Penerbit Jurusan Teknik Sipil FTSP-ITS, Surabaya, 2000.

[6] Mardianto Effendi, "Analisis Stabilitas Lereng Menggunakan Software Geostudio Slope/W 2012 Berdasarkan Metode Bishop Di Desa Cisarua, Kabupaten Bogor", Departemen Teknik Sipil dan Lingkungan, Fakultas Teknologi Pertanian InstitutPertanian Bogor, Bogor, 2016.

[7] Abramson, L.W., Lee, T.S., Sharma, S., and Boyce, G.M.. "Slope Stability and Stabilization Methods, John Wiley \& Sons Inc, 1996.

[8] Firaah, "Pemodelan Numerik Flownet Lubang Pori Untuk Tanah Pasir Berlempung dengan Software Geostudio Seep/W", Universitas Hasanuddin, Makasar, 2015.

[9] Babar and Arshad, "Comparison of Seep/W simulation with field observations seepage analysis through an Earthen Dam (Case Study : Hub Dam - Pakistan)", International Journal of Research (IJR)., Vol -1, Issue -7, ISSN 2348 - 6848, 2014.

[10] Wesley, Laurance D. "Mekanika Tanah untuk Tanah Endapan dan Residu."ANDI OFFSET, 2012

[11] Das, Braja M., "Mekanika Tanah (Prinsip-Prinsip Rekayasa Geoteknis) Jilid 1"Jakarta: Erlangga, 1998.

[12] Hardiyatmo, Hary Christady., "Mekanika Tanah 2 Edisi 6", Gadjah Mada University Press,2018. 